\begin{tabular}{l|l|l|l} 
Cose Reports in & $\begin{array}{l}\text { Case Rep Neurol 2009;1:1-7 } \\
\text { D01: 10.1159/000205406 }\end{array}$ & Published online: February 28, 2009 & $\begin{array}{l}\odot \text { 2009 S. Karger AG, Basel } \\
\text { ISSN 1662-680X } \\
\text { www.karger.com/crn }\end{array}$ \\
\hline
\end{tabular}

\title{
Refractory High Intracranial Pressure following Intraventricular Hemorrhage due to Moyamoya Disease in a Pregnant Caucasian Woman
}

\author{
Virginie Montiel $^{\mathrm{a}} \quad$ Cécile Grandin $^{\mathrm{b}} \quad$ Pierre Goffette $^{\mathrm{b}}$ \\ Edward Fomekong ${ }^{c}$ Philippe Hantson ${ }^{\mathrm{a}}$ \\ Departments of antensive Care, ${ }^{b}$ Neuroradiology, and 'Neurosurgery, Cliniques \\ St-Luc, Université Catholique de Louvain, Brussels, Belgium
}

\section{Key Words}

Pregnancy · Moyamoya syndrome - Intraventricular hemorrhage · Ventriculostomy · Intensive care management

\begin{abstract}
Intraventricular hemorrhage during pregnancy is usually followed by a poor recovery. When caused by moyamoya disease, ischemic or hemorrhagic episodes may complicate the management of high intracranial pressure. A 26-year-old Caucasian woman presented with generalized seizures and a Glasgow Coma Score (GCS) of 3 during the 36th week of pregnancy. The fetus was delivered by caesarean section. The brain CT in the mother revealed bilateral intraventricular hemorrhage, a callosal hematoma, hydrocephalus and right frontal ischemia. Refractory high intracranial pressure developed and required bilateral ventricular drainage and intensive care treatment with barbiturates and hypothermia. Magnetic resonance imaging and cerebral angiography revealed a moyamoya syndrome with rupture of the abnormal collateral vascular network as the cause of the hemorrhage. Intracranial pressure could only be controlled after the surgical removal of the clots after a large opening of the right ventricle. Despite an initially low GCS, this patient made a good functional recovery at one year follow-up. Management of refractory high intracranial pressure following moyamoya related intraventricular bleeding should require optimal removal of ventricular clots and appropriate control of cerebral hemodynamics to avoid ischemic or hemorrhagic complications.
\end{abstract}




\begin{tabular}{l|l|l|l} 
Cose Reports in & $\begin{array}{l}\text { Case Rep Neurol 2009;1:1-7 } \\
\text { Dol: } 10.1159 / 000205406\end{array}$ & & $\begin{array}{l}\text { Published online: February 28, 2009 S. Karger AG, Basel } \\
\text { ISSN 1662-680X } \\
\text { www.karger.com/crn }\end{array}$ \\
\hline
\end{tabular}

\section{Introduction}

Intracranial hemorrhage from moyamoya disease has been infrequently reported during pregnancy, and is exceptional in a Caucasian pregnant woman. The prognosis is usually severe. The intensive care management is also complicated as the patient may present both ischemic or hemorrhagic complications. We present a case with a favorable outcome despite a low Glasgow Coma Score (GCS) on admission and refractory high intracranial pressure.

\section{Case Report}

A 26-year-old Caucasian pregnant woman at 36 weeks of gestation presented to the Emergency Department of a first hospital for a severe headache. Her past medical history was not relevant. There was no sign of toxemia during pregnancy and no history of hypertension. She had delivered her first child 3 years ago without any complication. Soon after admission, she developed generalized tonicclonic seizures with a GCS at 3 immediately after seizure. A caesarian section was performed without any delay under general anesthesia and mechanical ventilation. The brain computerized tomography (CT) performed immediately after revealed extensive bilateral intraventricular hemorrhage and a large hematoma in the splenium of the corpus callosum. Routine laboratory tests including coagulation tests had normal results. An external ventricular drain was inserted bilaterally. Despite bilateral ventricular drainage and intensive care management, intracranial pressure (ICP) remained above $40 \mathrm{~mm} \mathrm{Hg}$. Diabetes insipidus was noted on day 2. Treatment with intravenous barbiturates and hypothermia was started. Hemodynamic conditions worsened and catecholamines administration (dobutamine and norepinephrine) was required. The patient was transferred to the university hospital on day 8 . On admission, GCS was $3 / 15$ with abolition of brainstem reflexes. Central body temperature was $32^{\circ} \mathrm{C}$. As the EEG showed burst suppression, barbiturate overdose was suspected and continuous infusion was stopped. Blood thiopental concentration was excessive $(68.8 \mu \mathrm{g} / \mathrm{ml})$. Cardiocirculatory status improved after barbiturate withdrawal. Echocardiography disclosed normal left ventricle contractility. However, high intracranial pressure persisted above $40 \mathrm{~mm} \mathrm{Hg}$. On brain CT (fig. 1), the size of the intraventricular hemorrhage had decreased on the left but not on the right side and the sulci were diffusely obliterated, confirming the intracranial hypertension. A right subcortical frontal ischemic lesion was also visible. The right drain was impinged in the ventricular clot and was ineffective, even after the in loco infusion of a fibrinolytic agent ( $5 \mathrm{mg} r \mathrm{rt}-\mathrm{PA}$ ), leading to refractory high intracranial pressure. Endoscopic removal of the right ventricular clots was first tried, but it was necessary to perform a larger right frontal craniotomy. Intracranial pressure decreased postoperatively but the GCS remained at $3 / 15$ with absence of brainstem reflexes. A brain magnetic resonance imaging (MRI) performed on day 20 showed the partial removal of the intraventricular clot with decreased ventricular size and reopening of the sulci. MR-angiography disclosed extensive arterial anomalies with occlusion of the right internal carotid artery (ICA), severe stenosis of the left ICA and of the M1 segment of the left middle cerebral arteries (MCA), occlusion of the left posterior cerebral artery, collaterals arising from the external carotid arteries, and an extensive abnormal vascular network appearing as multiple small collateral vessels developed mainly in basal cisterna and in the thalami (ig. 2). This pattern evoked a moyamoya syndrome that occurred very early in age as demonstrated by the hypoplastic right bony carotid canal (fig. 3). Perfusion-weighted MRI showed moderate hemodynamic disturbances in both hemispheres, predominant on the left side, with delayed time-to-peak, prolonged mean-transit time and a compensatory increased cerebral blood volume. Conventional cerebral angiography (day 39) confirmed these observations.

The patient was monitored in the neurosurgical intensive care unit (NICU) by a continuous measurement of jugular bulb venous oxygen saturation $\left(\mathrm{SvjO}_{2}\right)$. While normal values are in the range of $60-65 \%$, values ranging from $50-55 \%$ were obtained in our patient. These values were considered as relatively low in a patient who was mildly hypothermic $\left(35^{\circ} \mathrm{C}\right)$ and who had a remaining barbiturate impregnation as assessed by the EEG pattern and by the determination of serum thiopental concentration $(28.5 \mu \mathrm{g} / \mathrm{ml})$. Other factors that could have lowered $\mathrm{SvjO}_{2}$ were ruled out (hypoxia or hypercapnia). It was decided to optimize the intensive care therapy. Cerebral perfusion pressure (CPP) was maintained higher than $70 \mathrm{~mm} \mathrm{Hg}$ by a continuous norepinephrine infusion, with $\mathrm{PaO}_{2}>100 \mathrm{~mm}$ $\mathrm{Hg}, \mathrm{PaCO}_{2}>30 \mathrm{~mm} \mathrm{Hg}$, and hemoglobin concentration above $12 \mathrm{~g} / \mathrm{dl}$, with $\mathrm{SvjO}_{2}$ values reaching 60\% as a result. On day 16, brainstem reflexes reappeared and GCS was 6 (E1, V1, M4), improving to E4, V1, M5 two days later. The ventricular drainage was removed on day 20. The weaning from mechanical ventilation started on day 28 . The patient was discharged from the NICU on day 40 with a GCS of 


\begin{tabular}{l|l|l|l} 
Cose Reports in & $\begin{array}{l}\text { Case Rep Neurol 2009;1:1-7 } \\
\text { Dol: } 10.1159 / 000205406\end{array}$ & Published online: February 28, 2009 & $\begin{array}{l}\text { ○ 2009 S. Karger AG, Basel } \\
\text { ISSN 1662-680X } \\
\text { www.karger.com/crn }\end{array}$ \\
\hline
\end{tabular}

$11 / 15$. The follow-up at one year showed a good functional recovery. A revascularization procedure is currently discussed.

\section{Discussion}

Intracranial hemorrhage during pregnancy is, in most cases, caused by cerebral aneurysms, arteriovenous malformation, and rarely by moyamoya disease. Moyamoya disease is characterized by the formation of an abnormal vascular network, known as 'moyamoya vessels', secondary to the progressive stenosis or occlusion of the distal ICAs and proximal aspects of the main cerebral arteries. Its etiology is unknown and the clinical presentation of this rare condition is usually characterized by recurrent ischemic strokes. However, in young adults, a hemorrhagic type is also reported. Different possible causes of intracranial hemorrhage in moyamoya disease were debated: rupture of saccular aneurysm in the circle of Willis or small peripheral pseudoaneurysm, usually arising from the perforating arteries or choroidal arteries or rupture of fragile moyamoya vessels in the basal ganglia [1-3]. Intracranial hemorrhage at atypical sites such as callosal body and mesencephalon should raise suspicion of moyamoya disease. In the present case, no aneurysm or vascular malformation was detected. The origin of the intraventricular bleeding was likely a rupture of fragile moyamoya vessels in the corpus callosum. We excluded moyamoya syndrome secondary to irradiation of the head, Down syndrome, brain tumor, neurofibromatosis and meningitis. Intracranial hemorrhage from moyamoya disease has been infrequently reported during pregnancy, and is exceptional in a Caucasian pregnant woman in comparison with Asian women [4-7]. There is no firm evidence that pregnancy in patients with moyamoya disease is a risk factor for intracranial hemorrhage or cerebral ischemia. Our patient had an uneventful pregnancy and delivery 3 years before. However, it appears logical that intracranial hemorrhage usually occurs in and after the second trimester related to hemodynamic changes during pregnancy. The maternal prognosis of such bleeding is usually poor [8]. In a recent fatal case similar to our observation, a 29-year-old female developed intraventricular hemorrhage at 14 weeks of gestation, together with repeated bilateral cerebral infarction. Intensive care therapy included hypervolemia, hemodilution and induced hypertension. The patient died from brain herniation on the 16th day.

The possibility of arterial vasospasm after intraventricular bleeding due to moyamoya disease is still debated [9]. Vasospasm is observed not only after subarachnoid hemorrhage, but also in patients with ruptured arteriovenous malformations resulting in intraventricular hemorrhage without subarachnoid clot. In moyamoya disease, the patient's brain appears particularly vulnerable to ischemic conditions for several reasons: stenosis or occlusion of one or more major cerebral arteries, reduced caliber of the moyamoya vessels, and possible vasospasm.

The intensive care management of the patients presenting simultaneously with ischemic and hemorrhagic complications from moyamoya disease appears difficult, particularly when high intracranial pressure is also present. The first objective is to obtain an adequate control of intracranial pressure (ICP). Hemodynamic reserve for changes of intracranial perfusion pressure may be severely impaired in patients with moyamoya disease. Intraventricular hemorrhage results in hydrocephalus, followed by increased ICP. Because hemodynamic insufficiency and an increase in ICP may cause irreversible ischemia, resolution of increased ICP is critical for patients with moyamoya disease in terms of cerebral hemodynamics $[10,11]$. Ventricular drainage is the first measure, but may be ineffective when clots become obstructive. There are insufficient data to 


\begin{tabular}{l|l|l|l} 
Cose Reports in & $\begin{array}{l}\text { Case Rep Neurol 2009;1:1-7 } \\
\text { Dol: } 10.1159 / 000205406\end{array}$ & & $\begin{array}{l}\text { Published online: February 28, 2009 S. Karger AG, Basel } \\
\text { ISSN 1662-680X } \\
\text { www.karger.com/crn }\end{array}$ \\
\hline
\end{tabular}

recommend the local use of fibrinolytic agents, even if in some series they seemed to enhance clot lysis $[11,12]$. Endoscopic removal of the hematoma during ventriculostomy is a surgical option, or even, as in the present case, thrombectomy after craniotomy [13]. It seems also essential to avoid hypocapnia and hypotension. Hyperventilation is deleterious in moyamoya patients, showing that the abnormal vessels are hypersensitive to some physiologic parameters such as $\mathrm{pCO}_{2}$ [14]. The continuous monitoring of jugular bulb $\mathrm{SvjO}_{2}$ is extensively used for detecting episodes of cerebral hypoxia/ischemia. $\mathrm{SvjO}_{2}$ reflects the balance between cerebral oxygen delivery and consumption. It is determined by oxygen arterial saturation $\left(\mathrm{SaO}_{2}\right)$, hemoglobin concentration, cerebral blood flow, and cerebral metabolic rate of oxygen. In patients with traumatic brain injury, the ischemic threshold for $\mathrm{SvjO}_{2}$ is less than $50 \%$, but the value for other conditions is not precisely known. In the present case, $\mathrm{SvjO}_{2}$ values of $50 \%$ were considered as low in a patient who was mildly hypothermic and still under the influence of barbiturates. As ischemic lesions were demonstrated on the brain CT, we tried to optimize oxygen delivery by maintaining the $\mathrm{CPP}$ at $70 \mathrm{~mm} \mathrm{Hg}$, with also a special attention to respiratory parameters and to hemoglobin concentration. The patient did not develop new ischemic lesions. However, we agree that there are no literature data confirming that the therapy should be directly oriented to obtain $\mathrm{SvjO}_{2}$ values higher than $60 \%$.

In conclusion, intraventricular hemorrhage following moyamoya disease is a rare entity during pregnancy, particularly in Caucasian women. As some patients may have experienced a previous pregnancy without complication, it remains difficult to establish the risk factor directly related to pregnancy. The prognosis, usually poor, could be influenced by surgical removal of the clot, in case of refractory high ICP, and by the adequate management of hemodynamic and respiratory parameters, particularly in the type with both hemorrhagic and ischemic complications. Vasospasm is a possible complication that can not be easily demonstrated in this particular setting. The question if a revascularization procedure is effective to prevent rebleeding is not yet fully answered [15].

Fig. 1. Brain CT scan on day 8 showing bilateral (right $>$ left) intraventricular hemorrhage.

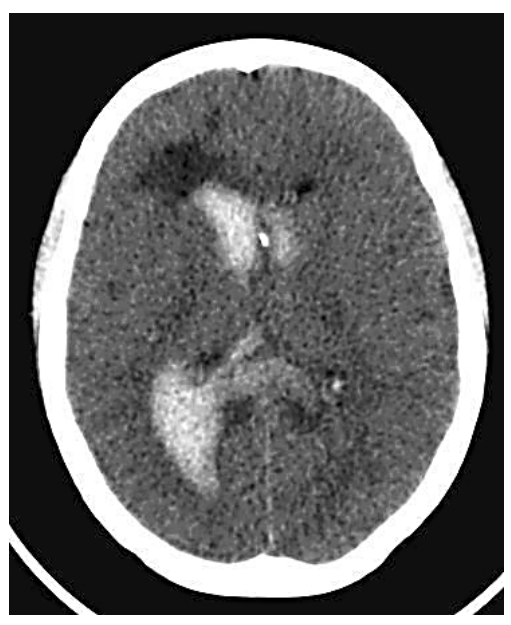




\begin{tabular}{l|l|l|l} 
Cose Reports in & $\begin{array}{l}\text { Case Rep Neurol 2009;1:1-7 } \\
\text { D0I: } 10.1159 / 000205406\end{array}$ & Published online: February 28, 2009 & $\begin{array}{l}\text { ○ 2009 S. Karger AG, Basel } \\
\text { ISSN 1662-680X } \\
\text { www.karger.com/crn }\end{array}$ \\
\hline
\end{tabular}

Fig. 2. Brain MR-angiography. Occlusion of the right internal carotid artery (ICA), severe stenosis of the left ICA and of the M1 segment of the left middle cerebral arteries (MCA), occlusion of the left posterior cerebral artery, collateral vessels (arrows) arising from the external carotid arteries, and an extensive abnormal vascular network appearing as multiple small collateral vessels developed mainly in basal cisterna and in the thalami.
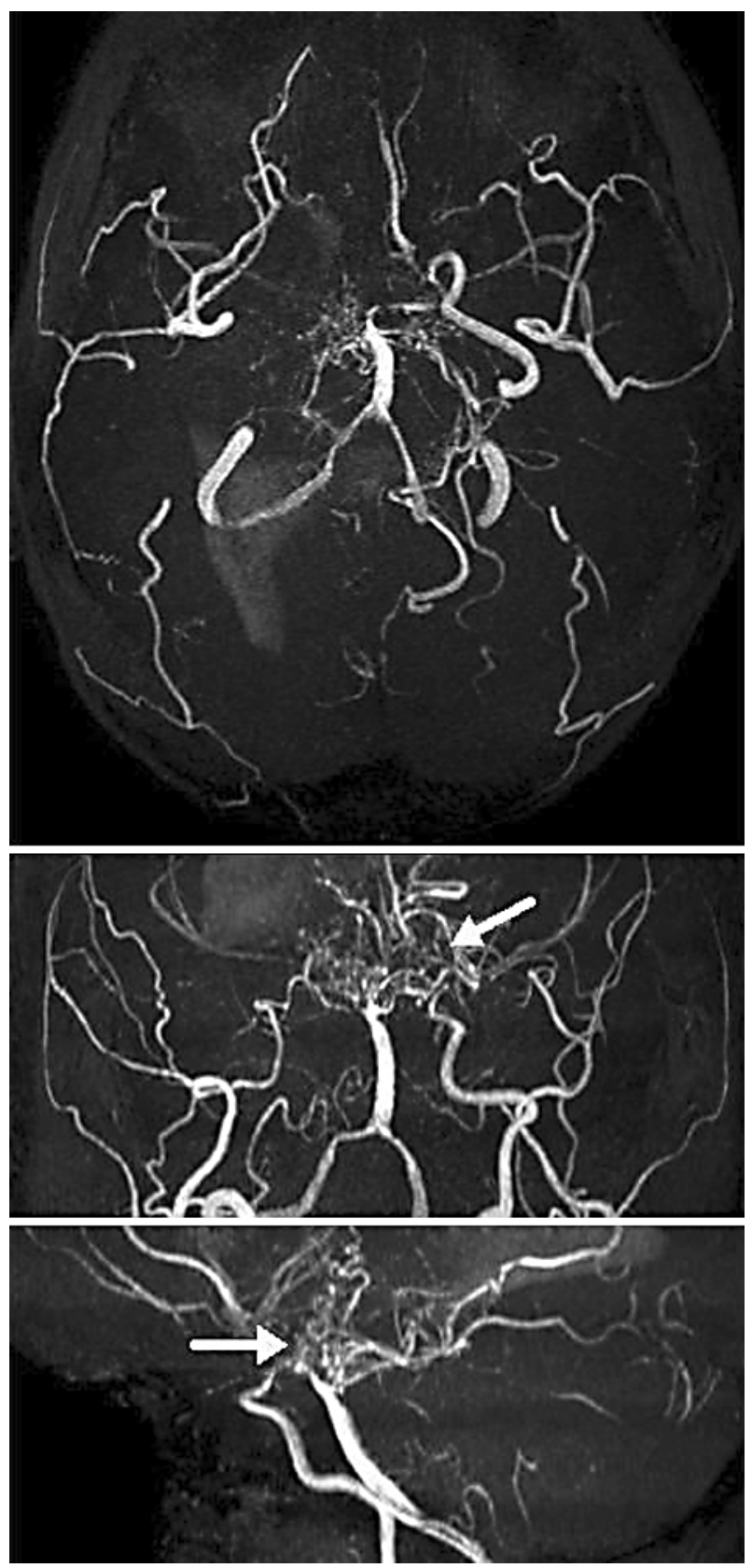


\begin{tabular}{l|l|l|l}
$\begin{array}{c}\text { Cose Reports in } \\
\text { Reulviojy }\end{array}$ & $\begin{array}{l}\text { Case Rep Neurol 2009;1:1-7 } \\
\text { D0I: 10.1159/000205406 }\end{array}$ & Published online: February 28, 2009 & $\begin{array}{l}\text { O 2009 S. Karger AG, Basel } \\
\text { ISSN 1662-680X } \\
\text { www.karger.com/crn }\end{array}$ \\
\hline
\end{tabular}

Fig. 3. Hypoplasic right bony carotid canal (arrow).

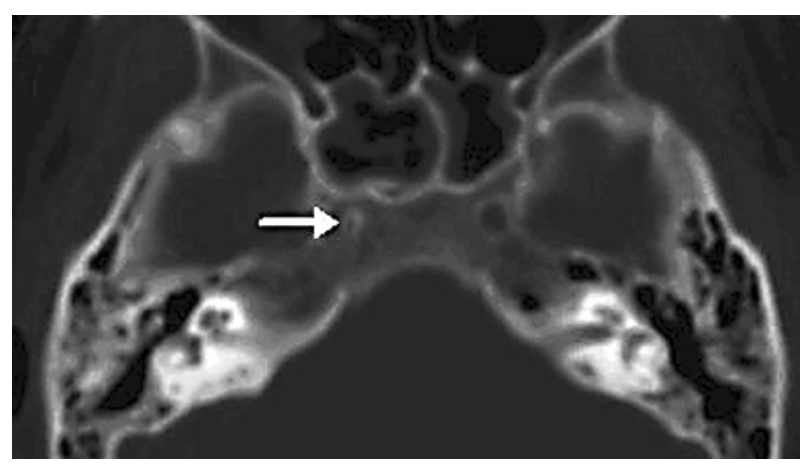




\begin{tabular}{l|l|l|l} 
Cose Reports in & $\begin{array}{l}\text { Case Rep Neurol 2009;1:1-7 } \\
\text { Dol: } 10.1159 / 000205406\end{array}$ & Published online: February 28, 2009 & $\begin{array}{l}\text { ○ 2009 S. Karger AG, Basel } \\
\text { ISSN 1662-680X } \\
\text { www.karger.com/crn }\end{array}$ \\
\hline
\end{tabular}

\section{References}

1 Hamada JI, Hashimoto N, Tsukahara T: Moyamoya disease with repeated intraventricular hemorrhage due to aneurysm rupture. J Neurosurg 1994;80:328331.

-2 Irikura K, Miyasaka Y, Kurata A, Tanaka R, Fujii K, Yada K, Kan S: A source of haemorrhage in adult patients with moyamoya disease: the significance of tributaries from the choroidal artery. Acta Neurochir (Wien) 1996;138:12821286.

-3 Morioka M, Hamada J, Kawano T, Todaka T, Yano S, Kai Y, Ushio Y: Angiographic dilatation and branch extension of the anterior choroidal and posterior communicating arteries are predictors of hemorrhage in adult moyamoya patients. Stroke 2003;34:90-95.

-4 Enomoto H, Goto H: Moyamoya disease presenting as intracerebral hemorrhage during pregnancy: case report and review of the literature. Neurosurgery 1986;20:33-35.

5 Hashimoto K, Fujii K, Nishimura K, Kibe M, Kishikawa T: Occlusive cerebrovascular disease with moyamoya vessels and intracranial hemorrhage during pregnancy - case report and review of the literature. Neurol Med Chir (Tokyo) 1988;28:588-593.

-6 Kim TS, Lee JH, Kim IY, Lee JK, Jung S, Kim JH, Kim SH, Kang SS: Moyamoya disease with repeated intracranial haemorrhage in two consecutive pregnancies. J Clin Neurosci 2004;11:525-527.

7 Williams DL, Martin IL, Gully RM: Intracerebral hemorrhage and Moyamoya disease in pregnancy. Can J Anaesth 2000;47:996-1000.

-8 Nakai Y, Hyodo A, Yanaka K, Nose T: Fatal cerebral infarction after intraventricular hemorrhage in a pregnant patient with moyamoya disease. J Clin Neurosci 2002;9:456-458.

-9 Yanaka K, Hyodo A, Tsuchida Y, Yoshii Y, Nose T: Symptomatic cerebral vasospasm after intraventricular hemorrhage from ruptured arteriovenous malformation. Surg Neurol 1992;38:63-67.

-10 Iwama T, Kotani Y, Yamakawa H, Nagata I, Hashimoto N, Sakai N: Cerebral ischemic complications following intracranial bleeding in patients with moyamoya disease - three case reports. Neurol Med Chir (Tokyo) 2001;41:450453.

11 Mehrkens JH, Steiger HJ, Strauss A, Winkler PA: Management of haemorrhagic type moyamoya disease with intraventricular haemorrhage during pregnancy. Acta Neurochir (Wien) 2007;148:685-689.

12 Naff NJ, Hanley DF, Keyl PM, Tuhrim S, Kraut M, Bederson J, Bullock R, Mayer SA, Schmutzhard E: Intraventricular thrombolysis speeds blood clot resolution: results of a pilot, prospective, randomized, double-blind, controlled trial. Neurosurgery 2004;54:577-583.

13 Horváth Z, Veto F, Balás I, Kövér F, Dóczi T: Biportal endoscopic removal of a primary intraventricular hematoma: case report. Minim Invasive Neurosurg 2000;43:4-8.

14 Maki Y, Enomoto T: Moyamoya disease. Child's Nerv Syst 1988;4:204-212.

15 Miyamato S: Study design for a prospective randomized trial of extracranialintracranial bypass surgery for adults with moyamoya disease and hemorrhagic onset - the Japan Adult Moyamoya Trial Group. Neurol Med Chir (Tokyo) 2004;44:218-221. 